\title{
Characterization of Diversity Among Isolates of Rhizoctonia oryzae-sativae from California Rice Fields
}

\author{
Patcharavipa Chaijuckam and R. Michael Davis, Department of Plant Pathology, University of California, Davis \\ 95616
}

\begin{abstract}
Chaijuckam, P., and Davis, R. M. 2010. Characterization of diversity among isolates of Rhizoctonia oryzae-sativae from California rice fields. Plant Dis. 94:690-696.

Thirty-one California isolates of Rhizoctonia oryzae-sativae, the cause of aggregate sheath spot of rice, were characterized by culture morphology, pathogenicity tests, somatic compatibility groups (SCGs), single-locus microsatellites (SLMs), and multilocus microsatellites (MLMs). The highest level of diversity (individual isolates) was described by MLMs whereas pathogenicity tests exhibited the lowest resolution. In general, a high degree of diversity was revealed (diversity from 51.6 to $100 \%$ ) within the California population. Several lines of evidence indicated sexual reproduction in the population of $R$. oryzae-sativae. Genetic analyses of SLMs and MLMs revealed high genetic diversity and gametic equilibrium of all SLMs and most MLMs. Furthermore, unique individuals were recovered by MLMs and there was no correlation of phenotypes to either SCGs or genetic markers. In addition, incongruence of parsimonious trees generated from each of five primers of MLMs and a poorly resolved consensus tree inferred from the combined data set were demonstrated. Accordingly, sexual reproduction of $R$. oryzaesativae is probably more prevalent in California than previously assumed.
\end{abstract}

Rhizoctonia solani is the most widely studied species in the genus Rhizoctonia (48). The genetics, anastomosis grouping, and pathogenicity of $R$. solani are well known because it is an economically important soilborne pathogen with a broad host range (40). In contrast, only a few studies have been concerned with $R$. oryzae-sativae (teleomorph, Ceratobasidium oryzaesativae), the causal organism of aggregate sheath spot. $R$. oryzae-sativae belongs to the $\mathrm{AG}-\mathrm{Bb}$ anastomosis group of binucleate Rhizoctonia spp. (17). The sexual stage of the fungus was first discovered in California rice fields in 1987 (19) on the outside of leaf sheaths as an indistinct whitish layer (17). Despite the occurrence of a sexual stage, aggregate sheath spot is considered a monocyclic disease with predominantly asexual reproduction (37). Overwintering sclerotia or mycelia in soil or crop residue probably serve as reservoirs of inocula $(17,18,27,37,38)$. A subsequent rice crop is infected by floating sclerotia in the rice paddy $(17,18,37)$.

Teleomorph induction can be difficult in Rhizoctonia spp.; therefore, classification

Corresponding author: R. M. Davis

E-mail: rmdavis@ucdavis.edu

Current address of P. Chaijuckam: Department of Plant Pathology, Kasetsart University, Kampaeng Saen Campus, Nakhon Pathom, 73140 Thailand.

Accepted for publication 6 February 2010.

doi:10.1094/PDIS-94-6-0690

(c) 2010 The American Phytopathological Society of new isolates of Rhizoctonia spp. has mostly been based on nuclear condition, colony morphology, anastomosis, and pathogenicity $(45,48)$. $R$. oryzae-sativae has been distinguished from other Rhizoctonia spp. by amplified fragment length polymorphism (49), specific primers (26), and fatty acid analysis (28). However, intraspecific genetic diversity of $R$. oryzaesativae has not been examined.

Somatic incompatibility has been used as a marker to identify clones of $R$. oryzaesativae in order to determine the survival of overwintering inoculum and dissemination of the fungus in rice fields in Japan (20). Isolates that have somatic incompatibility reactions produce growth inhibition zones or barrage zones due to plasmolysis of fused cells; this reaction occurs between genetically distinct isolates, whereas a compatible reaction produces confluent growth and living fusion of cytoplasm between isolates $(1,25,48)$. Compatible reactions are usually observed in self pairing and may indicate that the isolates are genetically similar $(25,48)$. However, some somatically compatible isolates of Suillus granulatus were genetically different after examination of DNA markers (25). Therefore, in this study, other methods in addition to somatic incompatibility tests were used to characterize $R$. oryzae-sativae.

Molecular techniques such as restriction fragment length polymorphisms, sequence analysis of rDNA, random amplified polymorphic DNAs, and random amplified microsatellites have been used to study genetic and taxonomy relationships within specific anastomosis groups of Rhizoctonia isolates $(10,45,47)$. In addition, microsatellites or simple-sequence repeats, which are widely dispersed in most eukaryotic and prokaryotic genomes $(9,51)$, have also been used to characterize diversity of Rhizoctonia spp. (10,34). The number of repeat units in a particular microsatellite region generates DNA polymorphism (43). These powerful tools have been used in genetic analyses of numerous organisms, including animals, plants, fungi, and humans, for the study of genomic evolution, population structure, gene flow, intraspecific phylogeny, mating systems, and genetic mapping $(3,9,43)$.

In this study, two types of microsatellites were employed, single-locus microsatellites (SLMs) and multilocus microsatellites (MLMs), to investigate diversity of $R$. oryzae-sativae. SLMs are recovered by amplification of the regions after specific primers bind to flanking regions (43); one or two alleles are expected at each locus for a binucleate $R$. oryzae-sativae isolate. MLMs are generated by using microsatellite hybridization probes as microsatellite primers in polymerase chain reaction (PCR); the primers bind to microsatellite regions and amplify the region between microsatellites, so that a fingerprint of $R$. oryzae-sativae isolate is obtained (35). The objectives of this study were to characterize intraspecific diversity of California isolates of $R$. oryzae-sativae based on culture morphology, pathogenicity tests, somatic compatibility groups (SCGs), SLMs, and MLMs and to examine modes of reproduction of this fungus.

\section{MATERIALS AND METHODS}

Collection and identification of isolates. Thirty-one $R$. oryzae-sativae isolates from rice sheaths with aggregate sheath spot symptoms were characterized in this study (Table 1). In total, 11 isolates were collected from a rice field in Colusa County (Colusa-1) in 2004 and 10 isolates were obtained from another field in Colusa (Colusa-3), and 1 field in Sutter counties (Sutter-2) in 2005. Field Colusa-1, Sutter2 , and Colusa- 3 are near the intersections of Tule and Poundstone Roads, Highway 45 and White Road, and Reclamation and Subaco Roads, respectively. Each of these fields is approximately 24 to 32 ha.

To isolate the fungus, a piece (about 4 to $9 \mathrm{~mm}^{2}$ ) from the margin of lesions was surface sterilized in $0.6 \%$ sodium hypochlorite (10\% bleach) for $3 \mathrm{~min}$ and 
plated on potato dextrose agar (PDA) + $0.01 \%$ gentamicin sulfate. Rhizoctonia spp-like cultures from these were transferred to PDA and incubated at room temperature (approximately $25^{\circ} \mathrm{C}$ ) for 2 weeks. A piece of each culture of $R$. oryzae-sativae isolate on PDA was placed in $1 \mathrm{ml}$ of sterile distilled water and maintained at $4^{\circ} \mathrm{C}$ for long-term storage.

All isolates were identified by their binucleate condition, morphological characteristics, and rDNA sequences. Nuclei were stained with the DNA-binding fluorochrome 4'-6'-diamidino-2-phenylindole and examined under UV light (15). The production of globose brown sclerotia and white to pale-brown mycelia on PDA after 2 weeks was diagnostic (17). Morphological characteristics used to identify $R$. oryzae-sativae included the appearance of T-cells and constricted hyphae (38).

The identity of all isolates was confirmed by internal transcribed spacer (ITS) sequences. To extract DNA, each isolate was cultured for 7 days in 125-ml Erlenmeyer flasks with $50 \mathrm{ml}$ of liquid media consisting of $20.7 \mathrm{~g}$ of D-glucose, $1.2 \mathrm{~g}$ of DL-asparagine, $1.2 \mathrm{~g}$ of $\mathrm{K}_{2} \mathrm{HPO}_{4} \cdot 3 \mathrm{H}_{2} \mathrm{O}, 0.5$ $\mathrm{g}$ of $\mathrm{MgSO}_{4} \cdot 7 \mathrm{H}_{2} \mathrm{O}, 0.5 \mathrm{~g}$ of yeast extract, and $0.1 \mathrm{~g}$ of $\mathrm{NaCl}$ per liter. Five $1.5-\mathrm{cm}^{2}$ agar plugs of each isolate were placed in liquid media and cultured for 7 days at room temperature without shaking. The mycelia were then filtered through Miracloth (Calbiochem, Gibbstown, NJ) and washed with sterile distilled water. About $200 \mathrm{mg}$ of mycelium was ground into a powder in liquid nitrogen. DNA from each isolate was extracted by the Dneasy Plant Mini Kit (no. 69104; Qiagen, Valencia, CA) following the manufacturer's protocol. rDNA of each isolate was amplified with primers ITS4 and ITS5 (53). The amplified products were purified with the QIAquick PCR Purification Kit (no. 28104; Qiagen) according to the manufacturer's instruction. The purified PCR products were sequenced with both primers using an ABI 3730 Capillary Electrophoresis DNA Analyzer (Applied Biosystem, Foster City, CA) at the College of Biological Sciences DNA Sequencing Facility, University of California-Davis. DNA sequences were compared to sequences in the National Center for Biotechnology Institute (NCBI) database.

Culture morphology characterization. $R$. oryzae-sativae isolates were grown on PDA at room temperature for 2 weeks. Qualitative culture characteristics, including colony color, aerial mycelia, and color and position of sclerotia, and quantitative culture characteristics, including growth rate and number of sclerotia, were examined. Growth rates of the isolates were determined by measuring colony diameter after 3 days on PDA. Numbers of sclerotia were determined on $1.5 \%$ water agar after cultures were incubated in the dark for 1 month. All experiments included four replications and were repeated once.

Pathogenicity tests. Rice tillers (9 weeks old) were cut into 20-cm-long pieces, washed in distilled water, surface sterilized in $0.6 \%$ sodium hypochlorite for $10 \mathrm{~s}$, blotted on paper towels, and placed in covered plastic crispers (31.1 by 22.9 by $10.5 \mathrm{~cm})$. Each rice stem was inoculated by placing one 7-day-old agar plug $(6 \mathrm{~mm}$ in diameter) of each isolate on the surface of the rice stem. High humidity was maintained by placing cotton moistened with sterile water on the agar plugs. The crispers were incubated at room temperature. Sterile agar plugs were used as controls. Length of the lesions was measured 4 days after inoculation. Two rice cultivars, M205 and M-206, were inoculated with each isolate. Treatments were replicated four times and the experiment was conducted three times.

SCGs. Mycelial disks (4 $\mathrm{mm}$ in diameter, 5 days old) of $R$. oryzae-sativae on PDA were paired with each other in all possible combinations. To confirm SCGs, three different media were used. The disks were approximately $2.5 \mathrm{~cm}$ apart on 5.6$\mathrm{cm}$-diameter petri plates containing PDA + $1 \%$ charcoal (6), PDA, or malt extract agar (24). All plates were incubated at room temperature in the dark for a week. Each pair was made on two plates of each media and repeated once. A barrage zone was indicative of a somatic incompatible reaction.

SLMs. Five primer pairs of SLMs were used to determine polymorphisms of $R$. oryzae-sativae isolates (Table 2). Genomic DNA of $R$. oryzae-sativae was extracted from lyophilized cultures by using TRIzol reagent and the manufacturer's protocol (Invitrogen, Carlsbad, CA). DNA concentration was calculated by using PicoGreen dsDNA quantitation reagent (Molecular Probes, Eugene, OR) and a SPECTRAFluor Plus fluorometer (Tecan, Durham, NC). After normalizing the concentration of fungal DNA, approximately $5 \mathrm{ng}$ of the DNA was used in each PCR, which was performed in 25- $\mu$ l volumes using the Qiagen HotStarTaq DNA polymerase with a 6-FAM-labeled primer. PCR was carried out in a Tetrad thermal cycler (MJ Research, Watertown, MA) with the following program: $15 \mathrm{~min}$ at $95^{\circ} \mathrm{C} ; 35$ cycles of $30 \mathrm{~s}$ at $94^{\circ} \mathrm{C}, 30 \mathrm{~s}$ at $60^{\circ} \mathrm{C}$, and $1 \mathrm{~min}$ at $72^{\circ} \mathrm{C}$; then, $10 \mathrm{~min}$ at $72^{\circ} \mathrm{C}$ as a final extension step. The amplified PCR products were separated with an ABI 3730xl DNA analyzer system and the fragment size was analyzed using the GeneScan 500 LIZ size standard (Applied Biosystem). The electropherogram data were analyzed by GENEMAPPER software (version 3.0; Applied Biosystem) to determine the size of products. Genotypic data were obtained by considering different product sizes as different alleles at each locus.

MLMs. Based on preliminary trials, five microsatellite primers were used to generate fingerprints, including MSD1, (GACA) MSD2, $(\mathrm{GTG})_{5}$; MSD3, (TGTC) $)_{4}$; MSD4, $(\mathrm{CA})_{8}(31,32)$; and MSD5, (AG) 8 . The primers bind at microsatellite regions and amplify the regions between microsatellite sequences. DNA of each isolates was extracted as described above and then amplified twice. The PCR was conducted in 50$\mu \mathrm{l}$ reactions containing $3.0 \mu \mathrm{l}$ of template DNA, $27.7 \mu \mathrm{l}$ of milliQ water, $2.0 \mathrm{mM}$ $\mathrm{MgCl}_{2}, 0.2 \mathrm{mM}$ of each dNTP, $1.0 \mu \mathrm{M}$ of the primer, 1× Promega GoTag Flexi reac-

Table 2. Single-locus microsatellite primers used in this study

\begin{tabular}{lllcc}
\hline Locus & $\begin{array}{c}\text { Repeat } \\
\text { motif }\end{array}$ & \multicolumn{1}{c}{ Primer sequence $\left(\mathbf{5}^{\prime} \mathbf{- 3}^{\prime}\right)$} & $\begin{array}{c}\text { No. of } \\
\text { alleles }\end{array}$ & $\begin{array}{c}\text { Amplified product size } \\
\text { (bp) }\end{array}$ \\
\hline P2 & TG & $\begin{array}{l}\text { F: ACGTCGTCGAGGAATTCTGT } \\
\text { R: ACGTGGAACCCCAGACATAG }\end{array}$ & 3 & $136-140$ \\
P7 & CT & $\begin{array}{l}\text { F: CGCTGACTTTGGTGAGCATA } \\
\text { R: AAAACAACCGATCCAGTGCT }\end{array}$ & 2 & $175-177$ \\
P20 & GGC & $\begin{array}{l}\text { F: CACAGGGTGACTACGGCAAC } \\
\text { R: GTAGCTCCCTCCATAGCCG }\end{array}$ & 3 & $96-105$ \\
P33 & CCGC & $\begin{array}{l}\text { F: CGTGTCTCGTACGTCTGCAT } \\
\text { R: GCTGACAGGGCTATCATTGG }\end{array}$ & 8 & $187-202$ \\
P37 & AC & $\begin{array}{l}\text { F: CAAACACCGAGAAGCAGGTT } \\
\text { R: GGGTGCAATTGCTGTTCATA }\end{array}$ & 8 & $165-172$ \\
All loci & $\ldots$ & ... & 24 & $\ldots$ \\
Mean & $\ldots$ & $\ldots$ & 4.8 & $\ldots$ \\
\hline
\end{tabular}

Table 1. Rhizoctonia oryzae-sativae isolates used in this study

\begin{tabular}{lllcl}
\hline Field & Year & County & No. of isolates & Isolate \\
\hline Colusa-1 & 2004 & Colusa & 11 & 101A, 102A, 103B, 109B, 1010A, 1011A, 1012B, 1013B, 1014A, 1016A, 1017B \\
Sutter-2 & 2005 & Sutter & 10 & 2705A, 2705B, 2706B, 2706C, 2706D, 2707A, 2707B, 2707D, 2708G, 2708H \\
Colusa-3 & 2005 & Colusa & 10 & 3709C, 3709D, 3709H, 3710A, 3710C, 3710E, 3711A, 3711F, 3712A, 3712C \\
\hline
\end{tabular}


tion buffer, and 1.5 units of GoTaq Flexi DNA polymerase (Promega Corp., Madison, WI; 32). The reaction was performed in a PTC-100 thermocycler (MJ Research) programmed for 40 cycles of $1 \mathrm{~min}$ at $94^{\circ} \mathrm{C}, 1 \mathrm{~min}$ at $50^{\circ} \mathrm{C}$, and $1.5 \mathrm{~min}$ at $72^{\circ} \mathrm{C}$ and an extension time at $72^{\circ} \mathrm{C}$ for $10 \mathrm{~min}$ (32). PCR products $(10 \mu \mathrm{l})$ were examined by $1.5 \%$ agarose gel electrophoresis and stained with ethidium bromide. The presence or absence of each band was scored for haplotypic data. Different fragments were considered as different loci.

Data analyses. The diversity of distinct culture morphologies, pathogenicity groups, SCGs, multilocus genotypes, and microsatellite fingerprinting patterns was determined. There was no significant difference of lesion expansion between cvs. M-205 and M-206 $(P=0.0638)$; therefore, data of all 31 isolates from both cultivars were combined. Moreover, there was no significant difference among trials for growth rate $(P=0.1747)$, number of sclerotia $(P=$ $0.1288)$, and virulence $(P=0.9571)$; therefore, data of all 31 isolates from independent trials were combined and analyzed together. Experiment trial was treated as a block term. The differences in growth rate, number of sclerotia, and ability to cause lesion expansion among all 31 isolates and among groups of isolates of individual fields were analyzed by analysis of variance. Means were separated by TukeyKramer highly significant difference (HSD) at $\alpha=0.05$ using JMP (version 7.0; SAS Institute Inc., Cary, NC).

Genotypic data of SLMs and haplotypic data of MLMs of all 31 isolates were used in genetic analyses. Gene diversity (39) of $R$. oryzae-sativae was calculated in POPGENE software (version 1.32; University of Alberta and Center for International Forestry Research, Alberta, Canada; 54). Genotypic diversity, computed in MULTILOCUS software (version 1.3; Department of Biology, University College London, Silwood Park, UK), was calculated by $(n / n$ $-1)\left(1-\Sigma p_{i}^{2}\right)$, where $p_{i}$ is the frequency of the $i$ th genotype and $n$ is the number of individuals sampled. Genotypic diversity is defined as the probability that two individuals taken at random have distinct genotypes. This value is 1 if every individual is different and 0 if every individual is the same (2).

To test the null hypothesis of random mating, gametic disequilibrium and HardyWeinberg equilibrium were measured. The significance levels for multiple comparisons of genetic analyses were adjusted by the sequential Bonferroni correction (44). Gametic disequilibrium was determined by the nonrandom relationship between pairs of loci, index of association $\left(I_{\mathrm{A}}\right)$, and $\bar{r}_{d}$. The nonrandom relationship between pairs of loci was analyzed by the likelihood ratio test (13) with 16,000 permutations for genotypic data of SLMs and by exact test using a Markov chain random walk (chain length: 10,000; dememorization: 1,000) according to Raymond and Rousset (42) for haplotypic data of MLMs in ARLEQUIN software (version 3.11; Zoological Institute, University of Bern, Switzerland; 12). $I_{\mathrm{A}}$, a multilocus measure of gametic disequilibrium (33), and $\bar{r}_{d}$, the modification of $I_{\mathrm{A}}$ to eliminate the dependency on number of loci (2), were computed in MULTILOCUS version 1.3. The significance of $I_{\mathrm{A}}$ or $\bar{r}_{d}$ was tested by comparing the observed value and the expected value under null hypothesis of random mating with 1,000 randomizations (2).

Haplotypic data of MLMs were analyzed by phylogenetic analyses using PAUP 4.0b10 (Sinauer Associates, Sunderland, MA). The most parsimonious trees for each primer were computed by heuristic searches and the congruence of trees from each primer was determined by the partition homogeneity test with 1,000 replications $(8,16)$. The consensus tree from combined data of five MLMs was also computed $(5,8)$.

Genotypic data of SLMs were used to test Hardy-Weinberg equilibrium (HWE) and inbreeding coefficient $\left(F_{\mathrm{IS}}\right)$ in POWERMARKER software (version 3.25; Bioinformatics Research Center, North Caro- lina State University, Raleigh; 30). The HWE test was performed by $\chi^{2}$ statistic, likelihood ratio test (52), and exact test (21). $F_{\text {IS }}$ for all five loci was calculated by method of moment (52). Because population structure could be the cause of departure from HWE and gametic disequilibrium (23), the number of populations $(K)$ of all 31 isolates from three fields was evaluated by STRUCTURE software (version 2.2; Department of Human Genetics, University of Chicago; 41). Ten runs were performed for each number of clusters $(K$ $=$ from 1 to $3 ; 10,000$ burn-in period; 10,000 Markov chain Monte Carlo steps after burn-in).

\section{RESULTS}

Identification of isolates, culture morphology characterization, pathogenicity tests, and SCGs. All isolates were identified as $R$. oryzae-sativae by the presence of T-cells, constricted hyphae, and binucleate cells. All shared identical ITS sequences, which were $99.7 \%$ similar to $R$. oryzae-sativae sequences in the NCBI database (e.g., accession no. AJ000192).

Most qualitative characteristics, including aerial mycelium and color and position of sclerotia, were variable, except colony color, which was consistently white (Table $3)$. Isolates from one field, Colusa-3, were less variable than the others; only two phenotypes of aerial mycelium and color of sclerotia were present. Qualitative culture morphology characteristics differentiated the $31 R$. oryzae-sativae isolates into 16 groups $($ diversity $=51.6 \%$ ) .

Growth rate and production of sclerotia were more variable among the 31 isolates than lesion expansion on rice tillers (Table 4). Based on the Tukey-Kramer HSD test at $\alpha=0.05$, the virulence of 30 isolates were not significantly different. At $\alpha=$ 0.05 , the mean growth rate and production of sclerotia by isolates from two fields, Sutter-2 and Colusa-3, were not significantly different from each other, whereas the mean growth rate and production of sclerotia by isolates from Colusa-1 were

Table 3. Qualitative culture morphology characteristics of Rhizoctonia oryzae-sativae isolated from three rice fields in California

\begin{tabular}{|c|c|c|c|c|c|c|}
\hline \multirow[b]{3}{*}{ Characteristic $^{y}$} & \multirow[b]{3}{*}{ No. of groups } & \multirow[b]{3}{*}{ Phenotype } & \multicolumn{4}{|c|}{ No. of isolates } \\
\hline & & & \multicolumn{3}{|c|}{ Field } & \multirow[b]{2}{*}{ Total } \\
\hline & & & Colusa-1 & Sutter-2 & Colusa-3 & \\
\hline \multirow[t]{3}{*}{ Aerial mycelium } & 3 & Slight & 3 & 4 & 6 & 13 \\
\hline & & Moderate & 5 & 3 & 4 & 12 \\
\hline & & Abundant & 3 & 3 & 0 & 6 \\
\hline Colony color & 1 & White & 11 & 10 & 10 & 31 \\
\hline \multirow[t]{3}{*}{ Color of sclerotia } & 3 & Light brown & 4 & 4 & 0 & 8 \\
\hline & & Brown & 6 & 4 & 9 & 19 \\
\hline & & Dark brown & 1 & 2 & 1 & 4 \\
\hline \multirow[t]{4}{*}{ Position of sclerotia } & 2 & Scattered all over the plate & 8 & 9 & 7 & 24 \\
\hline & & Aggregated at the center & 3 & 1 & 3 & 7 \\
\hline & 2 & On mycelia & 9 & 8 & 7 & 24 \\
\hline & & On mycelia + embedded in agar & 2 & 2 & 3 & 7 \\
\hline All characteristics ${ }^{\mathrm{z}}$ & 16 & $\ldots$ & $\ldots$ & $\ldots$ & $\ldots$ & 31 \\
\hline
\end{tabular}

\footnotetext{
y Two-week-old cultures on potato dextrose agar were examined.
}

${ }^{\mathrm{z}}$ Diversity was calculated as the number of distinct culture morphology groups relative to the total number of isolates. 
significantly lower and higher, respectively, than those variables by isolates from the other two fields. However, average lesion expansion caused by isolates from each of the three fields was significantly different from one another (Table 4).

Somatic incompatible reactions were consistent on all three media. There were 25 SCGs (diversity $=80.1 \%$ ) from 31 isolates. Only six pairs of isolates displayed somatic compatible reactions: two pairs from field Colusa-1 (109B+1013B and 1010A+1011A); two pairs from field Sutter-2 (2705A+2705B and 2707A+2707D); one pair from field Colusa-3 (3710A+ 3710E); and one pair between field Sutter2 and Colusa-3 (2707B+3711F).

SLMs and MLMs. In total, 24 alleles (an average of 4.8 alleles/locus) were amplified by five SLM primer pairs and all five SLMs were polymorphic (Table 5). There were 18, 20, and 19 total alleles and 2,3 , and 1 private alleles recovered in isolates from field Colusa-1, Sutter-2, and Colusa-3, respectively. In total, 15 alleles were found in all three fields; 1 and 2 alleles were shared between fields Colusa- 1 and Colusa-3 and fields Sutter-2 and Colusa-3, respectively. No allele was shared among the isolates from fields Colusa- 1 and Sutter2. SLM distinguished 28 multilocus genotypes (diversity $=90.3 \%$ ) among the 31 isolates. Three pairs of the same multilocus genotypes were detected $(109 \mathrm{~B}+1013 \mathrm{~B}$, $1010+1011 \mathrm{~A}$, and 2705A+2705B). Isolates of $R$. oryzae-sativae exhibited an average gene diversity of 0.61 and a high genotypic diversity of 0.99 for SLMs (Table 5). All five SLMs were in gametic equilibrium based on all three methods tested.

In total, 61 DNA fragments/loci (an average of 12.2 fragments/primer) were recovered by five MLM primers and 55 fragments $(90.2 \%)$ were polymorphic (Table 5). The number of DNA fragments ranged from 8 fragments for primers MSD2 and MSD5 to 18 fragments for primers MSD1 and MSD3. There were 54, 50 , and 39 total fragments present and 46, 42 , and 30 polymorphic fragments in isolates from Colusa-1, Sutter-2, and Colusa3 , respectively. There were nine (Colusa1), six (Sutter-2), and zero (Colusa-3) field-specific fragments. Six fragments were shared in every isolate from all three fields. One and two fragments were shared among isolates from fields Colusa- 1 and Colusa-3 and fields Sutter-2 and Colusa-3, respectively. No fragments were shared among the isolates from Colusa- 1 and Sutter-2. Based on all 61 fragments, all 31 isolates showed distinct fingerprinting patterns (diversity $=100 \%$ ). The average gene diversity of all isolates of $R$. oryzaesativae was 0.22 ; the highest genotypic diversity was 1.00 for MLMs (Table 5). There was significant multilocus gametic disequilibrium but only a few pairs of loci (3.8\%) were not randomly associated. Based on the partition of homogeneity test, the most parsimonious trees from each primer of MLMs were incongruent $(P=$ $0.001)$. The strict consensus tree of the 48 most parsimonious trees of $R$. oryzaesativae inferred from five MLM primers was not well resolved with some internal branches; the tree length was 209 steps (Fig. 1). The sum of tree lengths from all trees generated by each primer was 130 steps.

According to the analysis of populations in STRUCTURE, the most probable number of populations was one (i.e., there was no population structure among the isolates from the three fields and they could represent a single population without violating HWE and gametic equilibrium). The results of HWE tests and $F_{\text {IS }}$ with SLM data from 28 isolates, representing each different multilocus genotype, and from the total of 31 isolates were similar (data not pre- sented). Two SLMs, P2 and P20, were in HWE (Table 6). The other three SLMs (P7, $\mathrm{P} 33$, and P37) significantly deviated from HWE and had a positive $F_{\text {IS }}$ (heterozygote deficit). Overall, a deficit of heterozygotes was detected in four of five SLMs, including the locus P20, which was in HWE.

\section{DISCUSSION}

All 31 isolates of $R$. oryzae-sativae from three rice fields in California had identical rDNA-ITS sequences. In general, the isolates from fields Sutter-2 and Colusa-3 were the most closely related populations based on quantitative culture morphology, SCGs, SLMs, and MLMs. These two fields are approximately $11 \mathrm{~km}$ apart. This relationship may be due to common sampling years and the lack of population structure between these two rice-growing areas (P. Chaijuckam, unpublished data). None of

Table 4. Quantitative culture morphology characteristics and virulence of Rhizoctonia oryzae-sativae isolated from three rice fields in California ${ }^{\mathrm{v}}$

\begin{tabular}{|c|c|c|c|}
\hline Field, isolates ${ }^{w}$ & Growth rate $(\mathrm{cm} / \text { day })^{x}$ & No. of sclerotia ${ }^{y}$ & Lesion length $(\mathrm{cm})^{\mathrm{z}}$ \\
\hline \multicolumn{4}{|l|}{ Colusa-1 } \\
\hline $101 \mathrm{~A}$ & $2.29 \mathrm{cdefg}$ & $0.6 \mathrm{hi}$ & $2.59 \mathrm{ab}$ \\
\hline $102 \mathrm{~A}$ & $1.98 \mathrm{k}$ & $7.8 \mathrm{abcd}$ & $2.63 \mathrm{ab}$ \\
\hline $103 \mathrm{~B}$ & 2.14 ghij & 7.5 bcde & $2.89 \mathrm{a}$ \\
\hline 109B & $2.04 \mathrm{jk}$ & $11.1 \mathrm{ab}$ & $3.21 \mathrm{a}$ \\
\hline 1010A & $2.04 \mathrm{jk}$ & 0.0 & $2.92 \mathrm{a}$ \\
\hline $1011 \mathrm{~A}$ & $2.03 \mathrm{jk}$ & 1.3 fghi & $2.55 \mathrm{ab}$ \\
\hline $1012 B$ & $2.09 \mathrm{ijk}$ & $11.0 \mathrm{ab}$ & $2.37 \mathrm{ab}$ \\
\hline $1013 \mathrm{~B}$ & 2.20 defghi & $10.3 a b c$ & $2.72 \mathrm{ab}$ \\
\hline $1014 \mathrm{~A}$ & 2.16 fghij & $6.8 \mathrm{bcdef}$ & $3.14 \mathrm{a}$ \\
\hline $1016 \mathrm{~A}$ & $1.95 \mathrm{k}$ & $13.3 \mathrm{a}$ & $2.43 \mathrm{ab}$ \\
\hline 1017B & $2.33 \mathrm{bcde}$ & 6.5 bcdefg & $2.37 \mathrm{ab}$ \\
\hline Mean & 2.11 & 6.9 & 2.71 \\
\hline \multicolumn{4}{|l|}{ Sutter-2 } \\
\hline $2705 \mathrm{~A}$ & $2.36 \mathrm{bc}$ & $1.0 \mathrm{ghi}$ & $1.78 \mathrm{ab}$ \\
\hline $2705 \mathrm{~B}$ & 1.761 & 4.5 defghi & $2.38 \mathrm{ab}$ \\
\hline 2706B & $2.39 \mathrm{bc}$ & $0.1 \mathrm{i}$ & $2.19 a b$ \\
\hline $2706 \mathrm{C}$ & $2.25 \mathrm{cdefgh}$ & 2.1 defghi & $1.80 \mathrm{ab}$ \\
\hline 2706D & 2.26 cdefg & 5.0 cdefghi & $1.79 \mathrm{ab}$ \\
\hline 2707A & $2.28 \mathrm{cdefg}$ & 5.3 cdefghi & $1.17 \mathrm{ab}$ \\
\hline 2707B & $2.39 \mathrm{bc}$ & 6.3 bcdefgh & $1.86 \mathrm{~b}$ \\
\hline 2707D & $2.34 \mathrm{bcd}$ & 4.1 defghi & $2.35 \mathrm{ab}$ \\
\hline $2708 \mathrm{G}$ & $2.33 \mathrm{bcde}$ & 1.9 efghi & $2.46 \mathrm{ab}$ \\
\hline $2708 \mathrm{H}$ & $2.34 \mathrm{bcd}$ & 2.5 defghi & $2.01 \mathrm{ab}$ \\
\hline Mean & 2.27 & 3.3 & 1.98 \\
\hline \multicolumn{4}{|l|}{ Colusa-3 } \\
\hline $3709 \mathrm{C}$ & 2.18 efghij & 1.5 fghi & $2.07 \mathrm{ab}$ \\
\hline 3709D & $2.31 \mathrm{cdef}$ & 1.8 fghi & $2.43 \mathrm{ab}$ \\
\hline $3709 \mathrm{H}$ & $2.55 \mathrm{a}$ & 1.3 fghi & $2.76 \mathrm{ab}$ \\
\hline $3710 \mathrm{~A}$ & $2.39 \mathrm{bc}$ & 4.3 defghi & $3.17 \mathrm{a}$ \\
\hline $3710 \mathrm{C}$ & $2.28 \mathrm{cdefg}$ & 3.3 defghi & $2.19 a b$ \\
\hline $3710 \mathrm{E}$ & $2.36 \mathrm{bc}$ & 3.0 defghi & $2.08 \mathrm{ab}$ \\
\hline $3711 \mathrm{~A}$ & $2.48 \mathrm{ab}$ & $0.3 \mathrm{i}$ & $2.67 \mathrm{ab}$ \\
\hline $3711 \mathrm{~F}$ & $2.33 \mathrm{bcde}$ & $6.9 \mathrm{bcdef}$ & $2.21 \mathrm{ab}$ \\
\hline $3712 \mathrm{~A}$ & 2.10 hijk & $6.9 \mathrm{bcdef}$ & $1.75 \mathrm{ab}$ \\
\hline $3712 \mathrm{C}$ & 2.15 ghij & 4.8 cdefghi & $1.98 \mathrm{ab}$ \\
\hline Mean & 2.31 & 3.4 & 2.33 \\
\hline
\end{tabular}

${ }^{\mathrm{v}}$ Data were analyzed by analysis of variance (ANOVA); means in columns followed by the same letter are not significantly different at $\alpha=0.05$ according to Tukey-Kramer highly significant difference (HSD) test.

${ }^{\mathrm{w}}$ Mean $=$ means of growth rate, number of sclerotia, or virulence of isolates from each individual field. Differences in growth rate, number of sclerotia, and virulence among groups of isolates of individual fields were analyzed by ANOVA; means were separated by Tukey-Kramer HSD test at $\alpha=0.05$.

${ }^{x}$ Colony diameter after 3 days on potato dextrose agar. Data of all 31 isolates from two independent trials.

${ }^{y}$ Number of sclerotia produced on $1.5 \%$ water agar after 1 month. Data of all 31 isolates from two independent trials.

${ }^{\mathrm{z}}$ Lengths of lesions on rice tillers were measured 4 days after inoculation. Data of all 31 isolates from three independent trials. 
the microsatellite markers and SCGs of isolates from fields Colusa- 1 and Sutter- 2 were shared between these two fields, possibly because the isolates originated from different sampling years and areas.

MLMs provided the highest resolution for distinguishing $R$. oryzae-sativae isolates at the individual level whereas the pathogenicity test exhibited the lowest resolution. Culture morphology showed moderate resolution and SCGs and SLMs displayed high resolution. Some isolates in the same SCG had different multilocus genotypes but the isolates with the same multilocus genotypes were always in the same SCG. The higher resolution by SLMs was probably caused by faster divergence of employed microsatellites than SCGs (8). Molecular techniques may be more preferable than morphology for studying diversity in pathogens because morphological characteristics are dependent on culture environment and conditions (47).

Parasexual reproduction, which results in recombination of genetic material via mitosis, creates and maintains variation for asexual fungi (29). This mode of reproduction probably did not occur because many somatic incompatible reactions among the isolates of $R$. oryzaesativae were displayed, preventing genetic exchange (1).

Although the sexual stage of $R$. oryzaesativae is known to occur in California rice fields (19), the extent of sexual recombination in this fungus has never been examined. Aggregate sheath spot is presumed to be a monocyclic disease because a single generation of sclerotia affects the disease incidence in a subsequent rice crop (37). However, populations of $R$. oryzae-sativae sclerotia in rice seedbeds in California were not always correlated with subsequent levels of the disease (37). This phenomenon may be explained by the production of basidiospores as secondary inocula, an event probably more common than previously assumed.
Evidence of sexual reproduction was revealed in this study. A high diversity among $R$. oryzae-sativae isolates from California rice fields was detected based on culture morphology, SCGs, SLMs, and MLMs. MLMs, in particular, distinguished unique individuals, which may have been created from meiosis (22). However, there was low variation in the ability of the iso- lates to cause lesion expansion on rice tillers. Similarly, a lack of variation in virulence was documented in Sclerotinia sclerotiorum from Australian canola fields despite high genetic variation (46). Genetic analyses of SLMs and MLMs in this study also revealed high genetic diversity (high percentage of polymorphic loci and genotypic diversity). All SLM loci and most

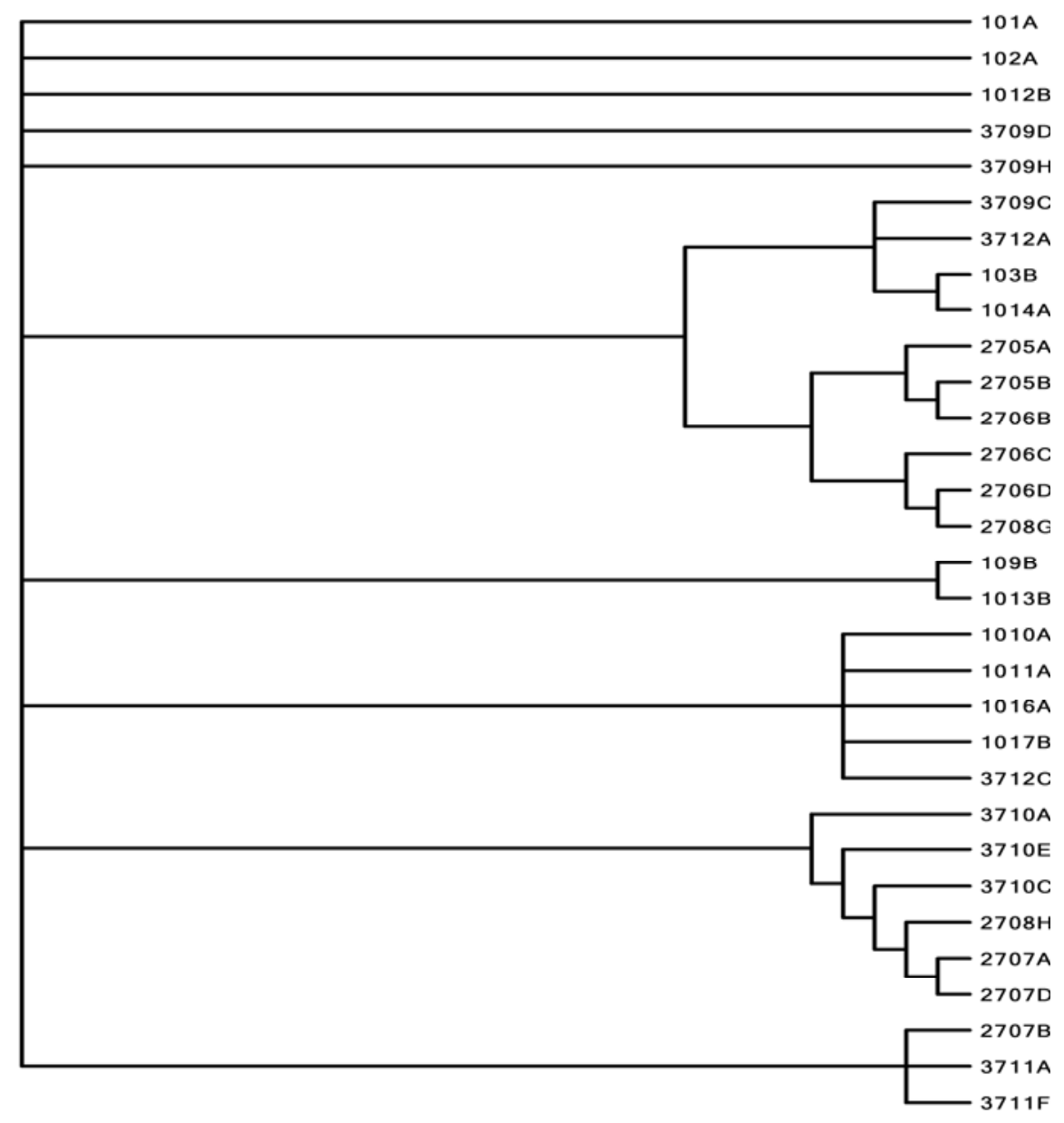

Fig. 1. Strict consensus tree of the 48 most parsimonious trees of Rhizoctonia oryzae-sativae inferred from five multilocus microsatellite primers. See Table 1 for identification of taxa.

Table 5. Genetic analyses of 31 Rhizoctonia oryzae-sativae isolates from three rice fields in California based on single-locus microsatellites (SLMs) and multilocus microsatellites (MLMs)

\begin{tabular}{|c|c|c|c|c|c|c|c|c|c|}
\hline \multirow[b]{2}{*}{ Marker } & \multirow[b]{2}{*}{ No. ${ }^{\mathrm{s}}$} & \multirow[b]{2}{*}{$\operatorname{Loci}(\%)^{t}$} & \multirow[b]{2}{*}{$\mathbf{M G s}^{\mathbf{u}}$} & \multirow[b]{2}{*}{ Diver. $(\%)^{\mathbf{v}}$} & \multirow[b]{2}{*}{ Avg.w } & \multirow[b]{2}{*}{ Genotype $^{x}$} & \multicolumn{3}{|c|}{ Gametic disequilibrium (GD) tests } \\
\hline & & & & & & & No. of pairs ${ }^{y}$ & $I_{\mathrm{A}}^{\mathrm{z}}$ & rBarD $^{z}$ \\
\hline SLMs & 24 & 100 & 28 & 90.3 & 0.61 & 0.99 & 0 of $10(0 \%)$ & $0.051(P=0.248)$ & $0.013(P=0.248)$ \\
\hline MLMs & 61 & 90.2 & 31 & 100 & 0.22 & 1.00 & 56 of $1,485(3.8 \%)$ & $0.816(P<0.01)$ & $0.016(P<0.01)$ \\
\hline
\end{tabular}

${ }^{\mathrm{s}}$ Number of alleles or fragments.

${ }^{\mathrm{t}}$ Total polymorphic loci $=5$ for SLMs and 61 for MLMs.

u Number of multilocus genotypes (MGs) or halotypes; genotypic data were obtained by considering different product sizes as different alleles at each locus for SLMs and the presence or absence of each band was scored for haplotypic data of MLMs.

${ }^{\mathrm{v}}$ Diversity was calculated as the number of distinct multilocus genotypes or haplotypes relative to the total number of isolates.

${ }^{w}$ Average gene diversity of $R$. oryzae-sativae was calculated according to Nei (39) in POPGENE version 1.32 .

${ }^{x}$ Genotypic diversity was calculated using MULTILOCUS version 1.3; the value of diversity is defined as the probability that two individuals taken at random have distinct genotypes, where the value is 1 if every individual is different, and 0 if every individual is the same (2).

${ }^{y}$ Nonrandom relationship between pairs of loci was analyzed by the likelihood ratio test (13) with 16,000 permutations for genotypic data of SLMs and by exact test using a Markov chain random walk (chain length: 10,000; dememorization: 1,000) according to Raymond and Rousset (42) for haplotypic data of MLMs in ARLEQUIN version 3.11. Values indicate the number of significant associated pairs of loci at $\alpha=0.05$ with sequential Bonferroni correction (44) out of the total pair tested.

${ }^{\mathrm{z}}$ Index of association $\left(I_{\mathrm{A}}\right)$ and $\mathrm{rBarD}$, the modification of $I_{\mathrm{A}}$ to eliminate the dependency on number of loci, were computed in MULTILOCUS version 1.3; the significance of $I_{\mathrm{A}}$ or $\mathrm{rBarD}$ was tested by comparing observed value and expected value under null hypothesis of random mating with 1,000 randomizations (2). 
pairs of MLM loci were in gametic equilibrium. Nonrandom association of alleles at different loci is expected to be low in sexually reproducing populations due to the decay of gametic disequilibrium by recombination over time $(22,36)$. Furthermore, some isolates in the same SCGs had different qualitative culture morphologies and some isolates with the same qualitative culture morphology were in distinct SCGs; this phenomenon also occurred between SLMs and features of culture morphology. Thus, there was no correlation of phenotypes with either SCGs or genetic markers, suggesting recombination (36). In addition, incongruence of parsimonious trees from each of the five primers of MLMs and the poorly resolved consensus tree inferred from combined data of the five primers further support sexual reproduction. Incongruence of topologies should be expected in sexual reproduction, whereas congruent topologies are expected when all genes are inherited together under clonal reproduction $(8,16)$. A longer and poorly resolved consensus tree of the combined data of the five MLM primers also indicated recombination. When sexual reproduction occurs, homoplasy may be introduced in a combined dataset because each gene may have had a different evolutionary history, resulting in a tree length longer than the sum of tree lengths of individual regions or genes. In contrast, all genes should have the same topology in clonal populations and the tree length of combined data should be similar to the sum of tree lengths from each gene, resulting in a short, well-resolved tree $(4,5,8,50)$.

Although sexual reproduction was apparent in $R$. oryzae-sativae, populations may not mate randomly. Heterozygote deficit may be the reason for deviation from HWE of three SLMs in this study. One locus that did conform to HWE also showed heterozygote deficit. Three plausible phenomena may result in inbreeding in $R$. oryzae-sativae, including selffertilization (homothallism), mating between siblings, or secondary homothallism. Homothallism may be less likely in $R$. oryzae-sativae because a homothallic sexual mode would result in low genetic diversity and a high degree of clonality in the population, and markers would tend to be nonrandomly associated and all loci would be homozygous (7). None of these characteristics was supported by the results in this study. Some conditions may promote mating between closely related relatives, such as sibling asci enclosed within a single ascocarp in Tuber spp. (4). This condition is less common for most Basidiomycetes because the wide dispersal of basidiospores decreases the chance of mating between sibling basidiospores (4). Secondary homothallism also increases homozygosity. The opportunity of inbreeding is higher in fungi bearing two-spored basidia, where two of four nuclei from meiosis migrate to each basidiospore. Indeed, binucleate basidiospores are not uncommon in Basidiomycetes (4). Mating behavior in some fungi could be complicated. Although Neurospora tetrasperma might sexually reproduce by secondary homothallism, it is also capable of infrequent heterothallic mating (outbreeding) (4). Agaricus bisporus is a well-known secondarily homothallic two-spored mushroom. Under random migration of nuclei after meiosis and the typical frequency of variation in the number of spores per basidium, $63,32,0.5$, and $4.5 \%$ of the individuals in an A. bisporus population produced a binucleate heterokaryon, binucleate homokaryon, monokaryon, and a mixture of monokaryon and dikaryon spores, respectively (14). In A. bisporus, the proportion of heterokaryotic basidiospores ( $88 \%$ or more) is higher than expected under random segregation due to the second meiotic division segregation $(4,11)$. Secondary homothallism may also be possible in $R$. oryzae-sativae because it has two-spored basidia (19), and 4 of the 5 SLMs displayed heterozygote deficit. However, the number of nuclei in its basidiospores, the ratio of dikaryon and monokaryon (if both are present), the mechanism of nuclear segregation in meiosis, and the breeding mode (homothallism or heterothallism) are still uncharacterized. Therefore, the hypothesis of secondary homothallism in $R$. oryzae-sativae needs further investigation.

Table 6. Tests for Hardy-Weinberg equilibrium and inbreeding coefficient $\left(F_{\mathrm{IS}}\right)$ of 28 (clone-corrected data) Rhizoctonia oryzae-sativae isolates from three rice fields in California based on five single-locus microsatellites $^{\mathrm{w}}$

\begin{tabular}{|c|c|c|c|c|c|c|}
\hline \multirow[b]{2}{*}{ Locus } & \multicolumn{2}{|c|}{$\chi^{2}$} & \multicolumn{2}{|c|}{ LTR $^{x}$} & \multirow{2}{*}{$\begin{array}{c}\text { Exact }^{\mathrm{y}} \\
P\end{array}$} & \multirow[b]{2}{*}{$F_{\text {Is }}{ }^{\mathrm{z}}$} \\
\hline & Value & $P$ & Value & $P$ & & \\
\hline $\mathrm{P} 2$ & 4.91 & 0.1784 & 6.16 & 0.1041 & 0.2450 & -0.2778 \\
\hline P7 & 23.13 & $0.0000^{*}$ & 24.17 & $0.0000 *$ & $0.0000 *$ & 0.9121 \\
\hline P20 & 1.61 & 0.6562 & 1.89 & 0.5962 & 0.5570 & 0.1503 \\
\hline P33 & 50.85 & $0.0052 *$ & 47.23 & $0.0130 *$ & $0.0000^{*}$ & 0.2650 \\
\hline P37 & 84.30 & $0.0000 *$ & 64.98 & $0.0001 *$ & $0.0000 *$ & 0.4849 \\
\hline
\end{tabular}

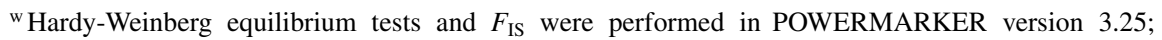

* indicates significant at $\alpha=0.05$ with sequential Bonferroni adjusted (44).

${ }^{\mathrm{x}}$ Likelihood ratio test (LTR) was calculated according to Weir (52).

${ }^{y}$ Exact test was computed according to Guo and Thomson (21).

${ }^{\mathrm{z}} F_{\mathrm{IS}}$ was computed by the method of moments (52).

It has been assumed that $R$. oryzaesativae reproduces primarily asexually and overwinters as sclerotia or mycelia, which play important roles in the epidemiology of aggregate sheath spot $(17,18,27,37,38)$. However, clones were not recovered in this study according to MLMs, which may be due to artifacts of small sample sizes or the potential differences in the distances of distribution of sexual and asexual inocula. Clones were perhaps mostly dispersed within fields because sclerotia produced by the fungus infected the next rice crop after overwintering $(17,18,37)$. Sexual reproduction is probably common in California. Airborne basidiospores may have the potential to disperse long distances and cause repeated infections. In general, sexual recombination may provide advantages to pathogens by resulting in new genotypes that adapt to environmental change, such as overcoming host resistance or fungicide toxicity (36). On the other hand, asexual reproduction may benefit pathogens because selection may promote the dissemination of successive genotypes that are not shuffled by recombination (36). The extreme variation in the population of $R$. oryzae-sativae indicated that various genotypes of $R$. oryzae-sativae should be included in screens for resistance genes in rice and other types of research, including efficacy of fungicides, to manage the disease.

\section{ACKNOWLEDGMENTS}

We thank the Royal Thai Government for financial support to P. Chaijuckam, M. Cubeta for advice on somatic incompatibility tests, C. A. Greer for rice seed, and R. Webster and D. Rizzo for helpful suggestions.

\section{LITERATURE CITED}

1. Adams, G. C. 1996. Genetics of Rhizoctonia species. Pages 101-116 in: Rhizoctonia species: Taxonomy, Molecular Biology, Ecology, Pathology and Disease Control. B. Sneh, S. Jabaji-Hare, S. Neate, and G. Dijst, eds. Kluwer Academic Publishers, Dordrecht, The Netherlands.

2. Agapow, P. M., and Burt, A. 2001. Indices of multilocus linkage disequilibrium. Mol. Ecol. Notes 1:101-102.

3. Barroso, G., Sonnenberg, A. S. M., Van Griensven, L. J. L. D., and Labarere, J. 2000. Molecular cloning of a widely distributed microsatellite core sequence from the cultivated mushroom Agaricus bisporus. Fungal Genet. Biol. 31:115-123.

4. Burnett, J. H. 2003. Fungal Populations and Species. Oxford University Press, New York.

5. Burt, A., Carter, D. A., Koenig, G. L., White, T. J., and Taylor, J. W. 1996. Molecular markers reveal cryptic sex in the human pathogen Coccidioides immitis. Proc. Natl. Acad. Sci. USA 93:770-773.

6. Butler, E. E., and Bolkan, H. 1973. A medium for heterokaryon formation in Rhizoctonia solani. Phytopathology 63:542-543.

7. Ceresini, P. C., Shew, H. D., James, T. Y., Vilgalys, R. J., and Cubeta, M. A. 2007. Phylogeography of the Solanaceae-infecting Basidiomycota fungus Rhizoctonia solani AG3 based on sequence analysis of two nuclear DNA loci. BMC Evol. Biol. 7:163.

8. Couch, B. C., and Kohn, L. M. 2000. Clonal spread of Sclerotium cepivorum in onion pro- 
duction with evidence of past recombination events. Phytopathology 90:514-521.

9. Douhan, G. W., and Rizzo, D. M. 2003. Amplified fragment length microsatellites (AFLM) might be used to develop microsatellite markers in organisms with limited amounts of DNA applied to arbuscular mycorrhizal (AM) fungi. Mycologia 95:368-373.

10. Elbakali, A. M., Lilja, A., Hantula, J., and Martin, M. P. 2003. Identification of Spanish isolates of Rhizoctonia solani from potato by anastomosis grouping, ITS-RFLP and RAMSfingerprinting. Phytopathol. Mediterr. 42:167176.

11. Evans, H. J. 1959. Nuclear behaviour in the cultivated mushroom. Chromosoma 10:115135.

12. Excoffier, L., Laval, G., and Schneider, S. 2005. Arlequin (version 3.0): an integrated software package for population genetics data analysis. Evol. Bioinform. Online 1:47-50.

13. Excoffier, L., and Slatkin, M. 1998. Incorporating genotypes of relatives into a test of linkage disequilibrium. Am. J. Hum. Genet. 62:171-180.

14. Flegg, P. B., Spencer, D. M., and Wood, D. A. 1985. The Biology and Technology of the Cultivated Mushroom. John Wiley \& Sons, Chichester, UK.

15. Gantotti, B. V., and Woodske, D. V. G. 1991. Nuclear staining of Colletotrichum gloeosporioides f. sp. malvae conidia with fluorescent and nonfluorescent stains. Biotech. Histochem. 66:7-13.

16. Geiser, D. M., Pitt, J. I., and Taylor, J. W. 1998. Cryptic speciation and recombination in the aflatoxin-producing fungus Aspergillus flavus. Proc. Natl. Acad. Sci. USA 95:388-393.

17. Gunnell, P. S. 1992. Aggregate sheath spot. Pages 24-25 in: Compendium of Rice Diseases. R. K. Webster and P. S. Gunnell, eds. American Phytopathological Society, St. Paul, MN

18. Gunnell, P. S., and Webster, R. K. 1984. Aggregate sheath spot of rice in California. Plant Dis. 68:529-531.

19. Gunnell, P. S., and Webster, R. K. 1987. Ceratobasidium oryzae-sativae sp. nov., the teleomorph of Rhizoctonia oryzae-sativae and Ceratobasidium setariae comb. nov., the probable teleomorph of Rhizoctonia fumigata comb. nov. Mycologia 79:731-736.

20. Guo, Q., Kamio, A., Sen Sharma, B., Sagara, Y., Arakawa, M., and Inagaki, K. 2006. Survival and subsequent dispersal of rice sclerotial disease fungi, Rhizoctonia oryzae and Rhizoctonia oryzae-sativae, in paddy fields. Plant Dis. 90:615-622.

21. Guo, S. W., and Thompson, E. A. 1992. Performing the exact test of Hardy-Weinberg proportion for multiple alleles. Biometrics 48:361-372.

22. Halkett, F., Simon, J. C., and Balloux, F. 2005. Tackling the population genetics of clonal and partially clonal organisms. Trends Ecol. Evol. 20:194-201.

23. Hartl, D. L., and Clark, A. G. 1997. Principles of Population Genetics, 3rd ed. Sinauer Associates, Sunderland, MA.

24. Hietala, A. M., Korhonen, K., and Sen, R. 2003. An unknown mechanism promotes somatic incompatibility in Ceratobasidium bi- corne. Mycologia 95:239-250.

25. Jacobson, K. M., Miller, O. K., Jr., and Turner, B. J. 1993. Randomly amplified polymorphic DNA markers are superior to somatic incompatibility tests for discriminating genotypes in natural populations of the ectomycorrhizal fungus Suillus granulatus. Proc. Natl. Acad. Sci. USA 90:9159-9163.

26. Johanson, A., Turner, H. C., McKay, G. J., and Brown, A. E. 1998. A PCR-based method to distinguish fungi of the rice sheath-blight complex, Rhizoctonia solani, $R$. oryzae and $R$. oryzae-sativae. FEMS Microbiol. Lett. 162:289-294.

27. Lanoiselet, V. M., Cother, E. J., Ash, G. J., Hind-Lanoiselet, T. L., Murray, G. M., and Harper, J. D. I. 2005. Prevalence and survival, with emphasis on stubble burning, of Rhizoctonia spp., causal agents of sheath diseases of rice in Australia. Australas. Plant Pathol. 34:135-142.

28. Lanoiselet, V. M., Cother, E. J., Cother, N. J., Ash, G. J., and Harper, J. D. I. 2005. Comparison of two total cellular fatty acid analysis protocols to differentiate Rhizoctonia oryzae and R. oryzae-sativae. Mycologia 97:77-83.

29. Leslie, J. F. 1993. Some mechanisms maintaining genetic variability in fungal populations. Pages 247-275 in: Biology of SclerotialForming Fungi. S. D. Lyda and C. M. Kenerly, eds. The Texas Agricultural Experiment Station, College Station.

30. Liu, K. J., and Muse, S. V. 2005. PowerMarker: an integrated analysis environment for genetic marker analysis. Bioinformatics 21:2128-2129.

31. Longato, S., and Bonfante, P. 1997. Molecular identification of mycorrhizal fungi by direct amplification of microsatellite regions. Mycol. Res. 101:425-432.

32. Ma, Z., Boehm, E. W. A., Luo, Y., and Michailides, T. J. 2001. Population structure of Botryosphaeria dothidea from pistachio and other hosts in California. Phytopathology 91:665-672.

33. Maynard Smith, J. M., Smith, Noel H., O'Rourke, Maria, and Spratt, Brian G. 1993. How clonal are bacteria? Proc. Natl. Acad. Sci. USA 90:4384-4388.

34. Meinhardt, L. W., Wulff, N. A., Bellato, C. M., and Tsai, S. M. 2002. Genetic analyses of Rhizoctonia solani isolates from Phaseolus vulgaris grown in the Atlantic Rainforest region of Sao Paulo, Brazil. Fitopatol. Bras. 27:259-267.

35. Meyer, W., Mitchell, T. G., Freedman, E. Z., and Vilgalys, R. 1993. Hybridization probes for conventional DNA fingerprinting used as single primers in the polymerase chain reaction to distinguish strains of Cryptococcus neoformans. J. Clin. Microbiol. 31:2274-2280.

36. Milgroom, M. G. 1996. Recombination and the multilocus structure of fungal populations. Annu. Rev. Phytopathol. 34:457-477.

37. Miller, T. C., and Webster, R. K. 2001. Soil sampling techniques for determining the effect of cultural practices on Rhizoctonia oryzaesativae inoculum in rice field soils. Plant Dis. 85:967-972.

38. Mordue, J. E. M. 1974. Rhizoctonia oryzaesativae. CMI (Commonw. Mycol. Inst.) Descr.
Pathog. Fungi Bact. No. 409.

39. Nei, M. 1973. Analysis of gene diversity in subdivided populations. Proc. Natl. Acad. Sci. USA 70:3321-3323.

40. Ogoshi, A. 1996. The genus Rhizoctonia Pages 1-9 in: Rhizoctonia species: Taxonomy, Molecular Biology, Ecology, Pathology and Disease Control. B. Sneh, S. Jabaji-Hare, S. Neate, and G. Dijst, eds. Kluwer Academic Publishers, Dordrecht, The Netherlands.

41. Pritchard, J. K., Stephens, M., and Donnelly, P. 2000. Inference of population structure using multilocus genotype data. Genetics 155:945959.

42. Raymond, M., and Rousset, F. 1995. An exact test for population differentiation. Evolution 49:1280-1283.

43. Razavi, M., and Hughes, G. R. 2004. Microsatellite markers provide evidence for sexual reproduction of Mycosphaerella graminicola in Saskatchewan. Genome 47:789-794.

44. Rice, W. R. 1989. Analyzing tables of statistical tests. Evolution 43:223-225.

45. Sen, R., Hietala, A. M., and Zelmer, C. D. 1999. Common anastomosis and internal transcribed spacer RFLP groupings in binucleate Rhizoctonia isolates representing root endophytes of Pinus sylvestris, Ceratorhiza spp. from orchid mycorrhizas and a phytopathogenic anastomosis group. New Phytol. 144:331-341

46. Sexton, A. C., and Howlett, B. J. 2004. Microsatellite markers reveal genetic differentiation among populations of Sclerotinia sclerotiorum from Australian canola fields. Curr Genet. 46:357-365

47. Sharma, M., Gupta, S. K., and Sharma, T. R. 2005. Characterization of variability in Rhizoc tonia solani by using morphological and molecular markers. J. Phytopathol. 153:449-456.

48. Sneh , B., Burpee, L., and Ogoshi, A. 1991 Identification of Rhizoctonia Species. American Phytopathological Society, St. Paul, MN

49. Taheri, P., Gnanamanickam, S., and Hofte, M. 2007. Characterization, genetic structure, and pathogenicity of Rhizoctonia spp. associated with rice sheath diseases in India. Phytopathology 97:373-383.

50. Taylor, J. W., Geiser, D. M., Burt, A., and Koufopanou, V. 1999. The evolutionary biology and population genetics underlying fungal strain typing. Clin. Microbiol. Rev. 12:126146.

51. Tenzer, I., Ivanissevich, S., Morgante, M., and Gessler, C. 1999. Identification of microsatellite markers and their application to population genetics of Venturia inaequalis. Phytopathology 89:748-753.

52. Weir, B. S. 1996. Genetic Data Analysis, 2nd ed. Sinauer Associates, Sunderland, MA

53. White, T. J., Bruns, T., Lee, S., and Taylor, J. 1990. Amplification and direct sequencing of fungal ribosomal RNA genes for phylogenetics. Pages 315-322 in: PCR Protocols: A Guide to Methods and Applications. M. A. Innis, D. H. Gelfand, J. J. Sninsky, and J. T. White, eds. Academic Press, San Diego, CA.

54. Yeh, F. C., and Boyle, T. J. B. 1997. Population genetic analysis of co-dominant and dominant markers and quantitative traits. Belg. J. Bot. 129:157. 